\title{
FIM DO CORTE MANUAL DA CANA-DE-AÇÚCAR NA MICRORREGIÃO DE ITUIUTABA (MG) E OS IMPACTOS PARA OS TRABALHADORES
}

\author{
END MANUAL OF SUGAR CANE CUT IN ITUIUTABA (MG) AND ITS IMPACTS FOR WORKERS
}

\author{
Patrícia Francisca de Matos', Marina Franco Fratari', Rogério Gonçalves de Carvalho¹ \\ ${ }^{1}$ Universidade Federal de Uberlândia (UFU), Uberlândia, MG, Brasil
}

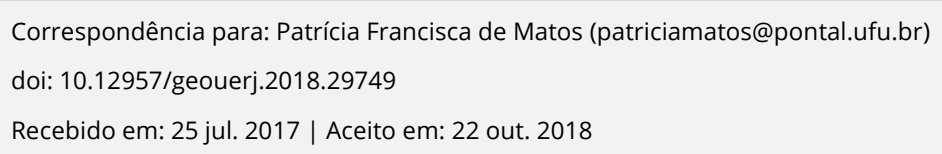

Recebido em: 25 jul. 2017 | Aceito em: 22 out. 2018

\section{SCREENED BY iThenticate}

\section{RESUMO}

A expansão da produção canavieira na Microrregião de Ituiutaba (MG) vem reestruturando o espaço agrário de todos os municípios, alterando as relações de produção, substituindo culturas, concentrando terras e modificando as relações de trabalho. A produção da cana-de-açúcar tem ocorrido por meio do arrendamento e parcerias de terras, o que leva à diminuição gradativa da produção diversificada de alimentos e culmina, assim, na monocultura da cana-de-açúcar. Como consequência da territorialização de usinas e da expansão da produção de cana, a mão-de-obra para o corte manual se fez presente. Todavia, a falência de duas usinas, a mecanização do corte da cana-de-açúcar e o fim das queimadas contribuíram para que os postos de trabalho do cortador de cana fossem extintos. Nesse contexto, torna-se importante mostrar as condições de vida e de trabalho do trabalhador cortador de cana da Microrregião de Ituiutaba, isto é, como tem sido sua inserção no mercado de trabalho, quais as principais dificuldades, tensões e incertezas que estão enfrentando.

Palavras-chave: Cana-de-açúcar; trabalho; precarização.

\begin{abstract}
The expansion of sugar cane cultivation in the Microregion of Ituiutaba (MG) is restructuring the agrarian space of all municipalities by changing the relations of production, replacing crops, concentrating land and modifying labor relations. The production of sugarcane has occurred through leasing and land partnerships, which leads to the gradual reduction of diversified food production and culminates thus the monoculture of sugar cane. Result of the installation of sugar cane agribusiness and expansion of sugarcane production, the hand labor migrant to the court was present. However, the bankruptcy of two sugarcane agribusiness, the mechanization of sugarcane and the end of burnings contributed to the cane cutter jobs were extinct. In this context, it is important to understand the conditions of life and work of the cane cutter worker in the Microregion, that is, as has been their integration into the labor market, what are the main difficulties, tensions and uncertainties they are facing.
\end{abstract}

Keywords: sugarcane; worker; precariousness.

\section{INTRODUÇÃO}

O Brasil tornou-se, há quase duas décadas, um importante produtor e consumidor de biocombustíveis, com destaque para o etanol. A necessidade de substituição dos combustíveis fósseis por "combustíveis limpos" conferiu uma posição de destaque ao etanol brasileiro. Com o mercado promissor, o Brasil tem sido palco de um crescimento do cultivo de cana-de-açúcar para produção de etanol, açúcar e energia. O estado de Minas Gerais conforme dados do IBGE (Instituto Brasileiro de Geografia e Estatística) constitui um dos maiores produtores de cana-de-açúcar do país, perdendo apenas para São Paulo e 
Goiás. A região do Pontal do Triângulo Mineiro tem se destacado no crescimento do setor, principalmente, a Microrregião Geográfica de Ituiutaba, a (Figura 1).

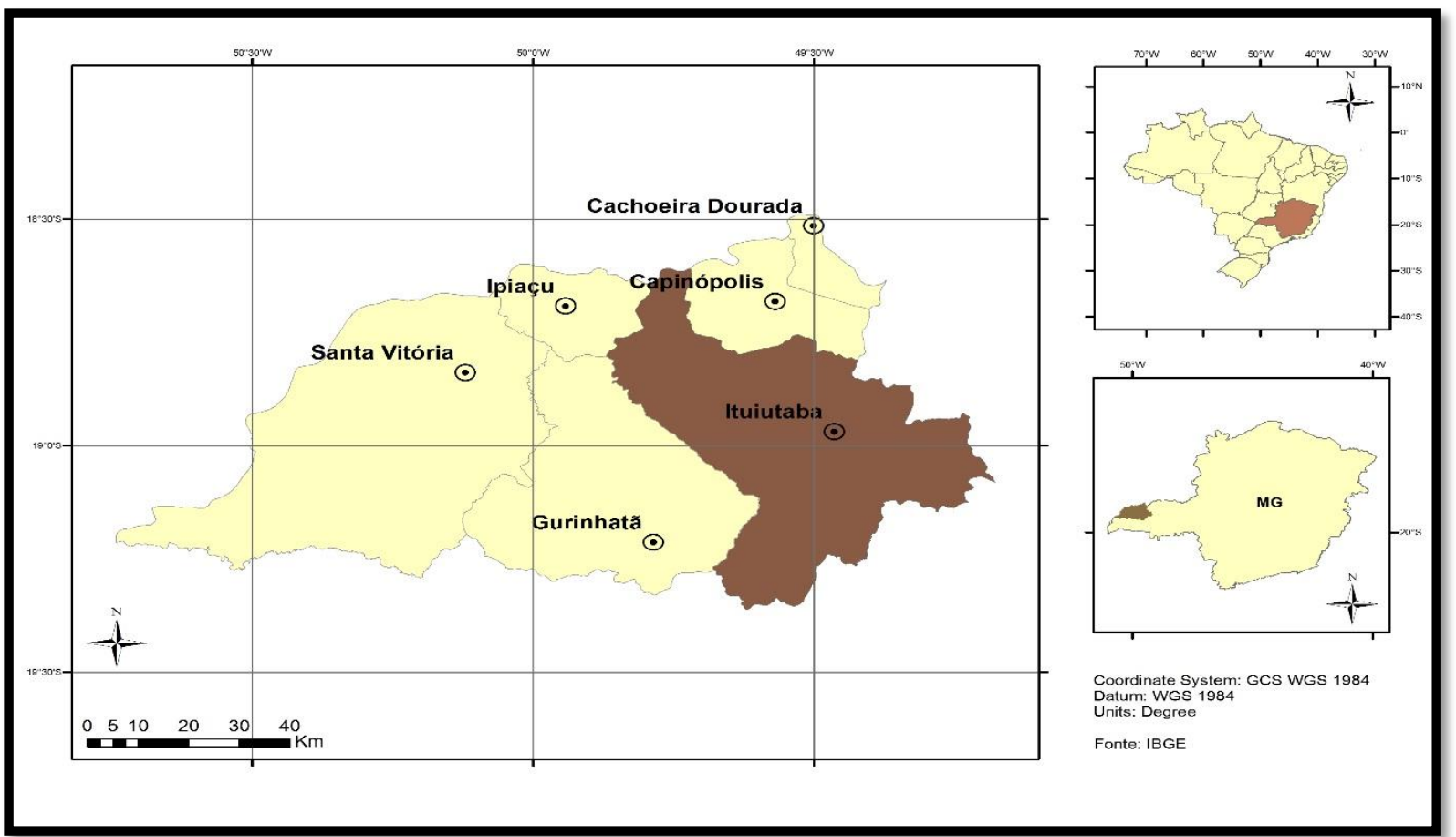

Figura 1. Microrregião Geográfica de Ituiutaba/MG. Elaboração: MACIEL, C, J.(2013)

A expansão da produção de cana-de-açúcar tem reestruturado o espaço agrário de todos os municípios da Microrregião de Ituiutaba, alterando as relações de produção, substituindo culturas e concentrando terras. O cultivo da cana-de-açúcar vem se expandindo em territórios de agricultura e da pecuária, situação particularmente visível nas propriedades localizadas no raio de 50 quilômetros das usinas, o que leva à diminuição gradativa da produção diversificada de alimentos e culmina na monocultura da cana-de-açúcar.

Como consequência da expansão das lavouras de cana, a mão-de-obra migrante para o corte da cana se fez presente nos municípios da Microrregião em cerca de dez anos (2003 a 2013). Para a colheita manual, os trabalhadores do Nordeste, especialmente do estado do Piauí e Alagoas, eram os preferidos das usinas, não apenas porque falta mão-de-obra local, mas porque para as usinas eles apresentavam mais resistência física e maior "submissão" às condições impostas pelas usinas. 
No ano de 2013, duas usinas tiveram suas atividades produtivas suspensas na Microrregião de Ituiutaba, gerando impactos, sobretudo, em relação aos empregos diretos e indiretos fornecidos. Nas lavouras, no período da colheita, havia cerca de mil trabalhadores no corte da cana. Ao término da colheita, muitos trabalhadores migrantes ficavam residindo em Ituiutaba ou em outras cidades da Microrregião enquanto outros retornavam às suas cidades de origem. A falência dessas usinas, a mecanização do corte da cana-de-açúcar e o fim das queimadas contribuíram para que os postos de trabalho do cortador de cana fossem extintos.

Em Minas Gerais, assim como em outros estados produtores, a colheita da cana-de-açúcar está em substituição do sistema tradicional, considerada a colheita manual da cana inteira com a queimada prévia do canavial, para o sistema de colheita mecanizada de cana sem queima do canavial. Uma das razões para essa substituição é a implementação de leis que preveem a redução gradativa das queimadas, sendo permitida apenas em áreas com declividade acima de 12\%, em razão da limitação do maquinário nessas áreas. Vários são os impactos sociais associados ao fim do corte manual, o principal deles é o desemprego dos trabalhadores.

A queima da cana-de-açúcar gera muitos impactos ambientais: altera as características do solo, degrada ecossistemas, ocorre a emissão de gases e poluição em razão da fumaça e da fuligem. Embora a mecanização e a proibição da queima apresentem um lado positivo para o meio ambiente, em contrapartida, geram prejuízos para os trabalhadores que perdem seus postos de trabalho. Para os trabalhadores, não é compensatório cortar cana crua, sem queimá-la e receber por produtividade, visto que um dos motivos da queima é justamente facilitar o processo da colheita. Conforme a fala de um trabalhador, consegue cortar, em média, 12 toneladas por dia de cana queimada, contra 6 toneladas de cana não queimada. Todavia, é importante destacar que não coube ao trabalhador decidir se querem cortar cana crua ou não, simplesmente, seu trabalho foi sendo substituindo pela máquina em função da produtividade.

Nesse contexto, objetiva apresentar, como tem sido a inserção no mercado de trabalho dos trabalhadores cortadores de cana, com fim do corte manual na Microrregião de Ituiutaba. A metodologia da pesquisa adotada pautou-se na abordagem qualitativa, por meio da aplicação no ano de 
2015 de formulários com oitenta trabalhadores que cortavam cana na região. Para a seleção dos trabalhadores levou-se em conta aqueles que trabalharam mais tempo na atividade, indicação dos próprios trabalhadores e do Sindicato, todos do sexo masculino, em função de na região, ter sido uma atividade predominantemente exercida por homens.

\section{A expansão da cana para as "terras" de Minas Gerais e a precarização do trabalho do cortador de cana-de-açúcar}

A partir dos anos de 2000, vários incentivos foram viabilizados pelo governo e também pela iniciativa privada, tanto nacional quanto internacional, possibilitando a expansão da produção de cana em diversas regiões do país, por conta da necessidade de substituição dos combustíveis fósseis por combustíveis "limpos" e do aumento da fabricação dos automóveis bicombustíveis. No Brasil a principal fonte de energia da matriz energética dos biocombustíveis é a cana-de-açúcar. Por isso, a expansão dessa cultura tem ocorrido em vários estados do país. Entre os estados que se destacam no processo dessa expansão, está o estado de Minas Gerais que ocupou em 2015 de acordo com os dados do IBGE o terceiro lugar, com 9,20 da produção nacional, perdendo posição apenas para o estado de São Paulo que representou, 56, 60\% e Goiás, 9,40\%. Minas Gerais, especificamente o Triângulo Mineiro, tornou-se território propício para crescimento do setor, em função dos fatores considerados primordiais e estratégicos: físicos (clima, solos, declividade, recursos hídricos), localização, logística, incentivos governamentais e legislação ambiental com poucas restrições.

\begin{tabular}{lcccccc}
\hline \multicolumn{1}{c}{ Região } & $\mathbf{1 9 7 5}$ & $\mathbf{1 9 8 5}$ & $\mathbf{1 9 9 5 / 6}$ & $\mathbf{2 0 0 5}$ & $\mathbf{2 0 1 0}$ & $\mathbf{2 0 1 5}$ \\
\hline Norte & 183.099 & 281.366 & 182.753 & 1.085 .211 & 2.071 .620 & 4.371 .436 \\
& & & & & \\
Nordeste & 31.130 .63 & 62.624 .054 & 47.075 .814 & 60.874 .754 & $68.789 . .20$ & 61.546 .275 \\
& 0 & & & & & \\
Sudeste & 45.432 .28 & 146.664 .43 & 173.073 .683 & 291.991 .211 & 498.884 .50 & 499.677 .593 \\
& 7 & 9 & & & & \\
Sul & 2.815 .269 & 12.327 .580 & 20.197 .769 & 24.659 .973 & 50.286 .221 & 48.587 .170 \\
Centro-Oeste & 423.915 & 7.984 .595 & 19.276 .684 & 37.777 .571 & 97.430 .026 & 134.453 .693 \\
\hline
\end{tabular}




\begin{tabular}{ccccccc}
\hline & 79.985 .20 & 229.882 .03 & 259.806 .70 & 326.121 .11 & 717.462 .10 & 748.636 .16 \\
Brasil & 0 & 4 & 3 & 1 & 7 \\
\hline
\end{tabular}

Tabela1. Produção (t) de cana-de-açúcar no Brasil e nas regiões, 1975 -2015. (anos selecionados).

A cultura da cana-de-açúcar está ligada à história econômica do Brasil. Quanto ao processo usineiro, este compreende a existência de quatros períodos (ANDRADE, 1994): o primeiro, com incentivos do governo imperial, nos anos 1870, para a criação de engenhos centrais; o segundo, com a criação do IAA (Instituto do Açúcar e do Álcool), para incentivar a produção de cana para o fabrico de açúcar e álcool; o terceiro se estendeu pelo período entre 1950 e 1970, caracterizado pelo desmoronamento das políticas do IAA; o quarto inicia-se nos anos de 1970, com as políticas públicas para modernizar e aumentar a produção da cana-de-açúcar, visando ao crescimento da produção do álcool, integrando-se, dessa forma, na política energética do país (MATOS, 2011).

Essas políticas foram projetadas devido à crise do petróleo, ocorrida na década de 1970, que gerou grande impacto sobre a economia de muitos países. Para minimizar o desequilíbrio na balança comercial brasileira, causado pela brusca elevação dos preços do petróleo, o Estado decidiu implantar políticas públicas para o setor energético, com o objetivo de criar alternativas energéticas, contrapondo-se à dependência do petróleo. O principal programa criado foi o PROÁLCOOL. Considerado um dos maiores programas mundiais de energia renovável, tinha o desígnio de estimular o crescimento dos canaviais, usinas e destilarias para a produção do álcool, buscando atender às necessidades do mercado interno e externo.

Após o PROÁCOOL, emergiu no início do século XXI, outras formas de investimentos do governo para expansão da produção dos biocombustíveis, que colocou novamente a cana como a principal opção na produção de álcool, promovendo nos lugares de territorialização do setor sucronergetico novas paisagens, novas formas de produção e novos usos do território. A Microrregião de Ituiutaba, considerado uma das principais áreas e expansão em Minas Gerais, ainda que se afirme a contribuição dessa monocultura para o crescimento econômico, é mais uma atividade agrícola responsável por inúmeros prejuízos sociais e ambientais. 
A produção da cana-de-açúcar gradativamente foi ocupando espaço na produção dos municípios de Microrregião de Ituiutaba (Figura 1) sobretudo, a partir de 2002, expandindo a área plantada e a produção. Os municípios de destaque na produção é Santa Vitória, Ituiutaba e Capinópolis, em função das usinas implantadas nesses municípios, juntos esses municípios produziram em 2015, 3.637.480 toneladas, em uma área de 76.214 hectares.
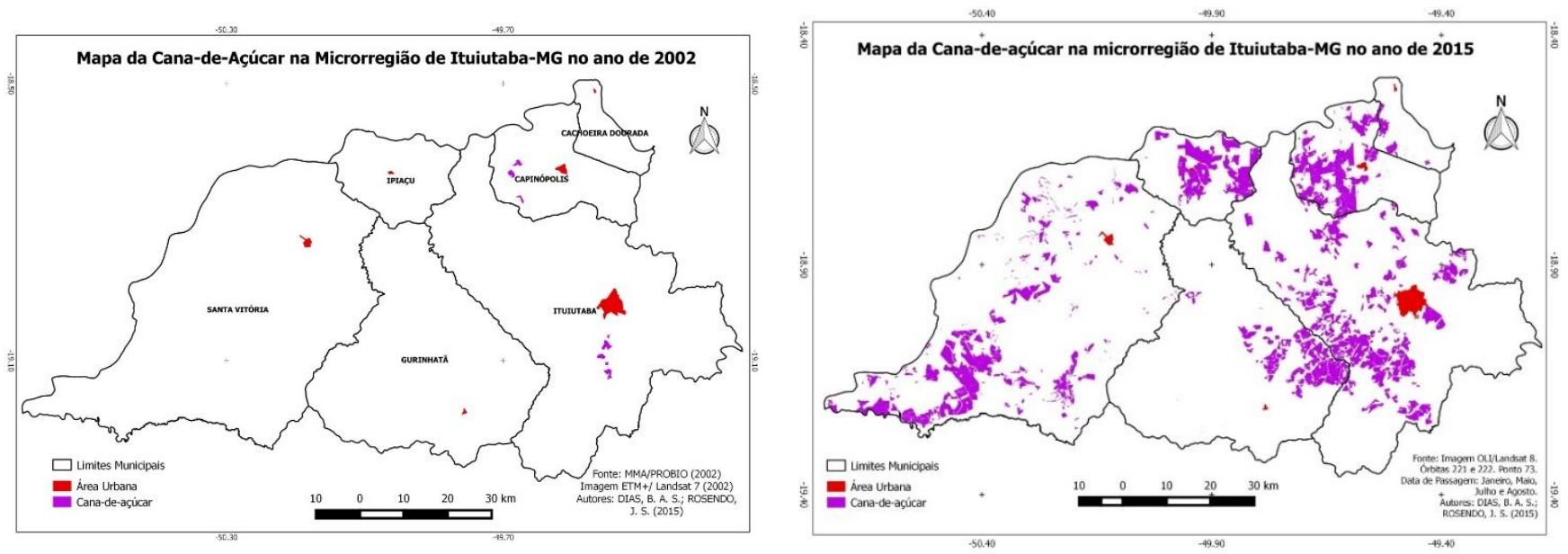

Figura 1. Expansão da cana-de-açúcar na Microrregião de Ituiutaba (2002-20015). Fonte: Mapeamento do uso da terra a partir de imagens de satélite dos anos de 2002 e 2015.

Importante destacar-se que as usinas da Microrregião de Ituiutaba investiram massivamente nos arrendamentos e parcerias, chegando algumas a produzirem na quase totalidade em terras arrendadas, visto que, para as usinas, o arrendamento tem sido uma opção rentável e a expansão da atividade requer uma grande quantidade de terra para o cultivo da cana-de-açúcar. Com isso, há, de certa forma, uma pressão por parte das usinas com os proprietários de terras para arrendar as terras, ou seja, há uma necessidade por parte das usinas em ocupar esses territórios, pois somente assim é possível aumentar a produção e, consequentemente, o capital. Isto tem possibilitado a modificação do processo produtivo dos municípios da Microrregião de Ituiutaba que têm apresentado aumento na produção da cana e a diminuição da produção de arroz, feijão, milho, hortaliças, entre outros, contribuindo, dessa forma, para o decréscimo da produção de alimentos a nível local e regional.

Em relação a colheita de cana, a Microrregião, durante vários anos, tornou-se polo de atração para trabalhadores que vinham trabalhar no período da safra e retornavam no final e, também, para os que 
permaneciam, trazendo sua família e fazendo dessa região seu lugar de residência. Estes trabalhadores, por sua vez, eram submetidos a formas precárias de trabalho, como relata o vídeo intitulado "Nas trilhas da cana", feito por membros do Grupo de Estudos e Pesquisas Agrárias e Trabalho - GEPEAT.

A perversidade e a precarização acompanham a trajetória do trabalho do cortador de cana. Uma das maiores dificuldades enfrentadas pelos trabalhadores é o esforço físico necessário na atividade do corte da cana e a exposição ao sol; passam o dia realizando movimentos repetitivos, sob rígido controle de um fiscal que determina a divisão dos eitos. Geralmente, os trabalhadores mais produtivos são colocados lado a lado, o que contribui para a competitividade entre eles. Não bastasse a extenuante jornada de trabalho e o esforço físico, não se alimentam de forma adequada e suficiente para repor as calorias gastas nas várias atividades do processo da colheita: cortar a cana rente ao solo; corte do pendão, transporte até o eito. Por isso, o ideal no processo da colheita, seria o trabalho em equipe, com rotação de tarefas e o salário não ser por produção.

\footnotetext{
Trata-se de uma forma de salário mais vantajosa ao capitalista uma vez que a intensidade do trabalho não depende dos investimentos em capital constante, mas do próprio trabalhador. É um salário que reforça as diferenças de habilidade, força, energia, perseverança dos trabalhadores individualmente, provocando diferenças nos seus rendimentos e o estabelecimento de concorrência entre eles. Esta competição estimula o aumento da intensidade do trabalho e, consequentemente, da produtividade. (SILVA,1999, p.86).
}

A autora adverte, ainda, que

\begin{abstract}
O mecanismo de controle externo acaba sendo introjetado pelo próprio trabalhador, de tal forma que ele se transforma em autocontrole, deixando de ser um controle de atos para ser do próprio indivíduo. Isto é conseguido por intermédio da forma de pagamento (por tonelada) e também pela concorrência velada que se estabelece entre os trabalhadores, diferenciando-os, hierarquizando-os. Produz-se, assim, a figura do "bom cortador de cana", aquele que corta em torno de dez toneladas diárias. Aqueles que estão muito abaixo desta média sentem-se incapazes, envergonhados, inferiorizados. (SILVA, 1999, p. 202, grifos da autora).
\end{abstract}

Como forma de pagamento, as usinas utilizam a produção, uma espécie de armadilha, porquanto "obriga" o trabalhador a trabalhar de forma intensa para ter melhor remuneração. Para Santos (2013, p. 169), 
dia seguinte. Assim, pode-se afirmar que o trabalhador trabalha sempre num ritmo alucinante porque seu salário é insuficiente para satisfazer todas as suas necessidades de reprodução social, quer sejam as necessidades materiais como as de moradia, vestimenta e alimentação, quer sejam as necessidades espirituais que envolvem o lazer, sociabilidade e sua formação. (SANTOS,2013, p. 169).

Mediante a artimanha do capital, o aumento da exploração sobre o trabalhador ganha expressividade, como exemplo é possível citar que para ser considerado produtivo na década de 1980, um trabalhador precisava cortar de 8 a 10 toneladas de cana por dia, enquanto que em 2010 esse número aumentou para cerca de 15 toneladas por dia. Ou seja, cada vez mais cobra-se o esforço físico, sendo comum o acirramento de doenças e/ou a morte dos trabalhadores.

Para Santos (2013, p.178), o extenuante esforço físico executado pelo cortador de cana, somado ao ambiente poluído com hidrocarbonetos e material particulado fruto das queimadas da cana, ocasiona o aparecimento de alguns sintomas no trabalhador, entre eles doenças cardiovasculares e respiratórias, resultantes do ambiente e das condições de trabalho. Alves (2006), no trabalho intitulado "Por que morrem os cortadores de cana?", comenta a rotina de trabalho de um cortador de cana-de-açúcar, mostrando com detalhes o processo ao qual está submetido nesta atividade produtiva.

O capital não tem qualquer preocupação social com o trabalhador que exerce e/ou exercia sua atividade laboral nos canaviais espalhados pelo território brasileiro, sendo resultado de novas diretrizes do capital interessado na redução de custos, conforme destaca Mendonça em entrevista ${ }^{1}$

\footnotetext{
O capital só mantem a mecanização porque é lucrativa em algumas áreas, ele faz a conta entre o investimento com as máquinas e o investimento com homens e mulheres com braços com trabalho vivo, então o capital vai sempre fazer a matemática entre o uso do trabalho morto e o uso do trabalho vivo e ele vai mecanizar se for conveniente a ele, ele não está preocupado com as condições existenciais do trabalhador [...] o que vale para os proprietários dos meios de produção é o quanto ganham é o que podem ganhar, seja com máquinas que é o trabalho morto mas e trabalho social, seja com trabalho vivo que é exatamente a apropriação da mais valia.
}

Com o processo de mecanização da colheita, os trabalhadores que se ocupavam do corte da cana perderam seus postos de trabalho. Assim como em demais regiões do país, os cortadores não tiveram

\footnotetext{
${ }^{1}$ Entrevista concedida ao GEPEAT (Grupo de Estudos e Pesquisas Agrárias e Trabalho) em 28 março de 2013.
} 
acesso a cursos técnicos de capacitação para outras atividades e/ou políticas compensatórias que pudessem (re)inserí-los no mercado de trabalho, aumentando o número de desempregados.

\section{Fim do corte manual da cana-de-açúcar na Microrregião de Ituiutaba (MG) e os impactos para os trabalhadores}

Os resultados da pesquisa demonstraram que no período da colheita da cana, geralmente, de maio a outubro, havia nas cidades da Microrregião de Ituiutaba uma concentração de migrantes, em sua maioria, dos estados do Nordeste. Com o fim do corte manual, uma parcela desses trabalhadores retornou para seus locais de origem enquanto centenas de pessoas estabeleceram residência na região, em busca de inserção no mercado de trabalho formal e informal. Dos ex-cortadores de cana entrevistados, a maioria (60\%) reside na Microrregião de Ituiutaba há mais de cinco anos, os demais (40\%) estão na região há menos de cinco anos.

Sobre o tempo de trabalho no corte manual, $24 \%$ deles trabalharam no corte de 6 a 10 anos; $60 \%$ estão entre 1 e 5 anos, somente 16\% mais de 10 anos. Em relação à idade dos trabalhadores, 40\% têm entre 40 e 50 anos e 48\%, entre 20 e 40 anos, (Figura 2), comprovando, que essa atividade exige trabalhadores mais jovens, em função, da expropriação da força física. Apesar de jovens, apresentam problemas de saúde causados pela precarização do trabalho do corte da cana.

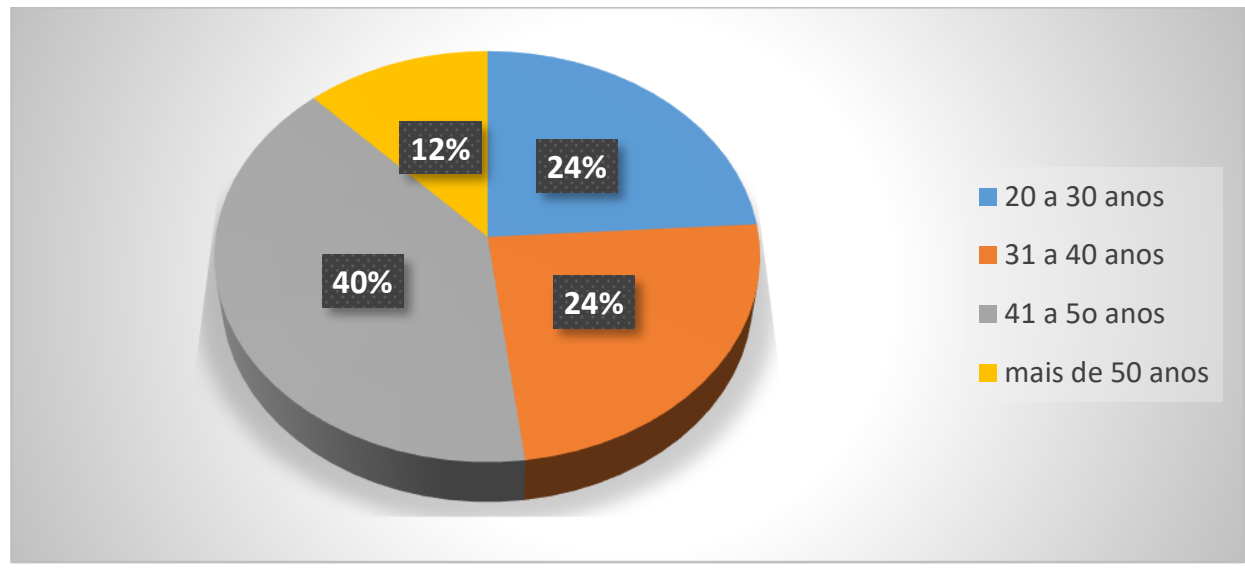

Figura 2. Perfil etário dos trabalhadores que cortavam cana na Microrregião de Ituiutaba (MG). Fonte: Trabalho de Campo (2015). Org.: CARVALHO,R,G (2016) 
Na pesquisa foi constatada a baixa escolaridade desses trabalhadores, com $64 \%$ possuindo apenas 0 ensino fundamental, $8 \%$ o ensino médio e $28 \%$ são analfabetos. Isto colaborou para que eles continuassem a trabalhar de forma precária, sujeitando-se à exploração de sua força de trabalho. Sem formação escolar, esses trabalhadores encontram dificuldades para se inserirem no mercado de trabalho, sobretudo, com carteira assinada, direitos e cobertura em caso de desemprego e doenças, conforme depoimento de trabalhadores que possuem apenas o ensino fundamental incompleto.

Se eu tivesse pelo menos uma leitura boa, conseguia tirar carteira de motorista para arrumar um emprego de tratorista ou caminhão, mais a vida toda foi lidar com trabalho braçal. O sonho é ter uma carteira assinada, para viver mais tranquilo. (Entrevistado A)

Eu não conseguir terminar os estudos, não consegui fazer nenhum curso técnico, porque sempre trabaiei em serviço pesado e não tinha ânimo pra ir pra escola, hoje vejo o tanto que faz falta, porque todo emprego com carteira assinada, os camaradas pedi estudo. Mais, nunca pensava que que as usinas ia deixar agente na mão, como se nois fosse descartável. (Entrevistado B

A pouca escolaridade é comprovada também quando detectadas as atividades em que esses trabalhadores foram inseridos após o fim do corte da cana na região (Figura 3). A maioria, 36\%, passou a trabalhar como servente, entre outros tipos de trabalho que exigem grande esforço físico e não tem carteira de trabalho assinada como serviços gerais e o auxiliar agrícola. Esses serviços, recebem por dia de trabalho e, as vezes, são esporádicos, ficando sempre a incerteza se no final do mês terá a quantia necessária para pagar as contas básicas em dia. Às vezes, para complementar a renda, trabalham também nos finais de semana. Com carteira assinada, foi constatado apenas os trabalhadores que laboram como motoristas e no comércio, somando um total de $20 \%$, e $12 \%$ relataram que no momento da pesquisa estavam desempregados, dependendo, inclusive de cestas básicas fornecidas pelo Sindicato dos trabalhadores ou outras instituições. 


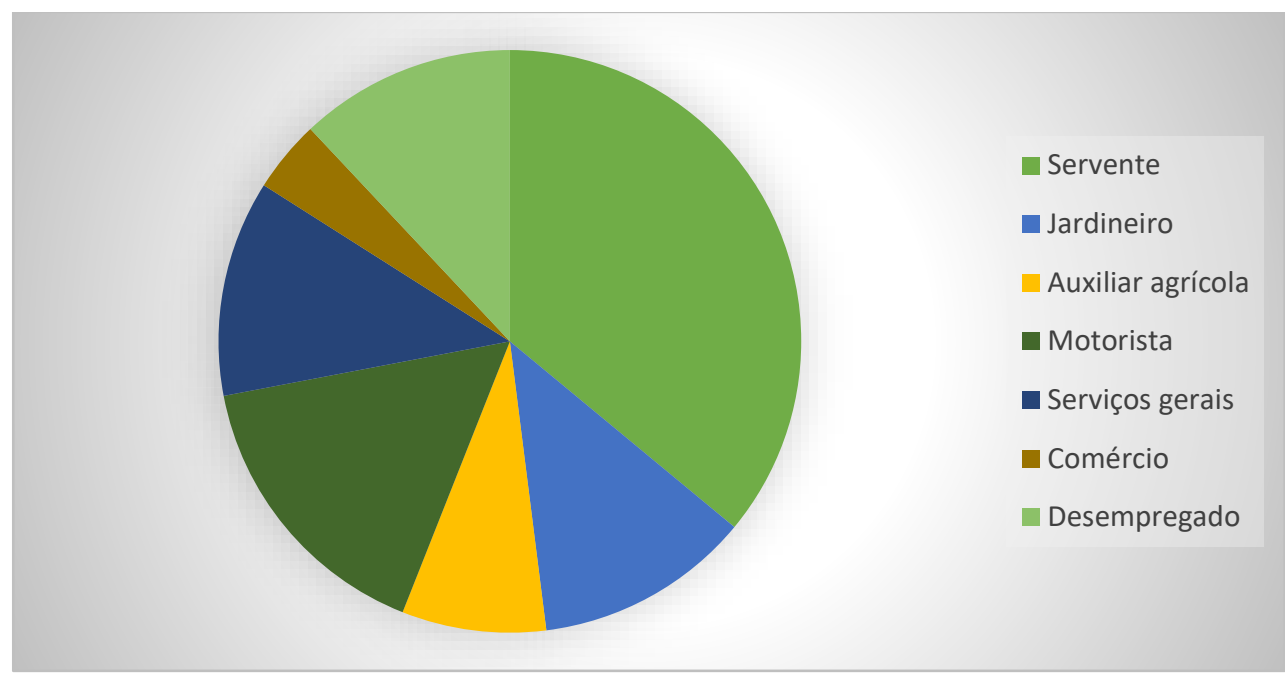

Figura3. Ocupação atual dos trabalhadores que cortavam cana na Microrregião de Ituiutaba (MG). Fonte: Trabalho de Campo (2015). Org.: Carvalho, R. G., 2016.

Com relação aos salários, 52\% afirmaram ter rendimentos entre 1 e 2 salários, inferior ao que recebiam na atividade do corte da cana, e 36\%, até 3 salários (Figura 4). Quando questionados se voltariam a trabalhar no corte da cana, 64\% responderam que sim, apesar de terem consciência das condições a que são submetidos nesse tipo de atividade; $32 \%$ disseram que não, em função do desgaste físico e da idade.

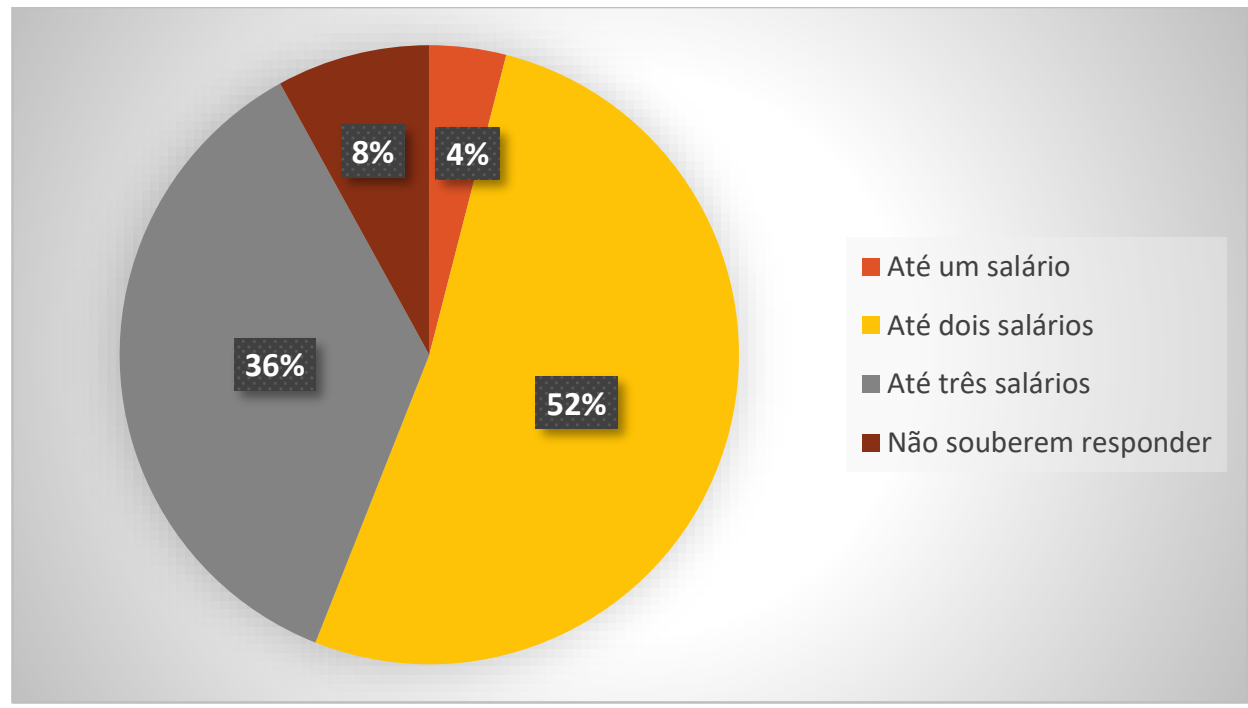

Figura 4. Rendimento atual mensal dos trabalhadores que cortavam cana na Microrregião de Ituiutaba (MG). Fonte: Trabalho de Campo (2015). Org.: Carvalho, R. G., 2016

Uma das principais reclamações dos trabalhadores é em relação ao salário recebido, uma vez que, no corte da cana seus rendimentos eram superiores, uma das razões que os motivariam a voltar a 
trabalhar nesta atividade. Convém destacar, mais uma vez, que salário do trabalhador está atrelada à quantidade de cana cortada por dia, constituindo uma forma perversa de remuneração, pois é a força de trabalho - a produtividade - que garantirá seu ganho.

Para Thomaz Junior (2002, p. 20):

Os sistemas de remuneração no corte de cana (como as formas de medição, classificação e pagamento) são armas importantes, disponibilizadas pelo capital, que garantem a um só tempo a manutenção da extração do sobretrabalho, como também o controle do processo de trabalho e da superexploração do trabalho, que chega às raias da semi-escravidão.

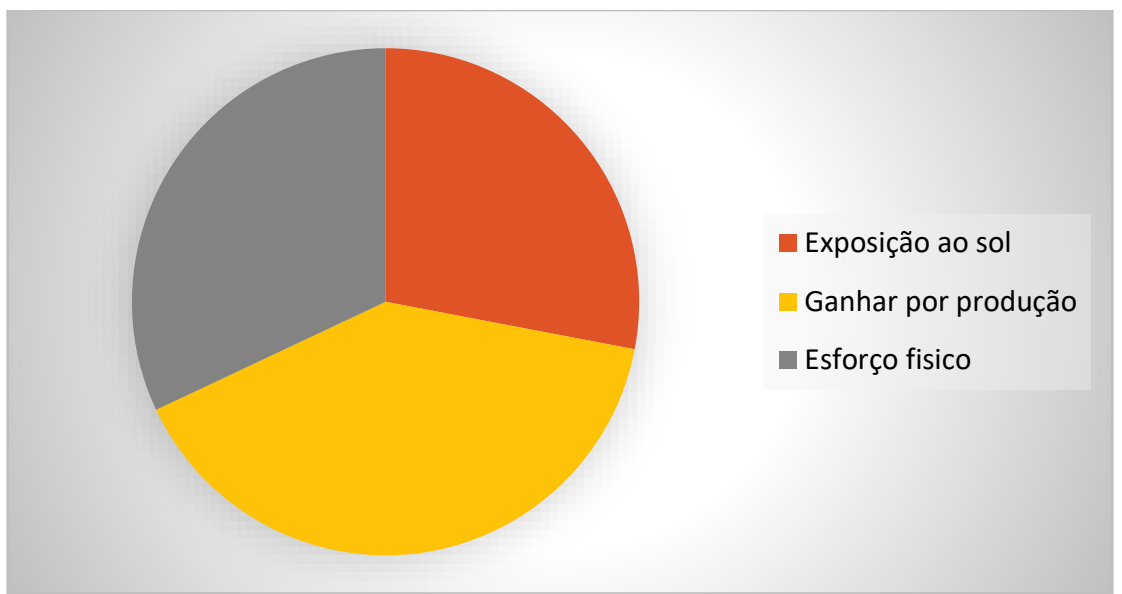

Figura 5. dificuldades enfrentadas no corte da cana. Fonte: Trabalho de Campo (2015). Org.: Carvalho, R. G., 2016.

Nesse contexto, o processo de mecanização atingiu o corte da cana, em que as colheitadeiras substituíram o trabalho humano, promovendo a extinção quantitativa desses postos de trabalho e 0 desemprego de milhares de trabalhadores. Mais uma vez, vivencia-se a conjuntura de uma "nova" etapa da modernização conservadora e perversa, sem políticas públicas que minimizem os impactos sociais.

\section{CONSIDERAÇÕES}

A expansão da cana-de-açúcar na Microrregião de Ituiutaba promoveu muitas transformações econômicas, ambientais e sociais. No que se refere aos trabalhadores do corte da cana, durante mais de dez anos esta atividade fornecia centenas de vagas, o que atraiu migrantes, principalmente, da região Nordeste do Brasil. Com a falência de duas usinas na área e a substituição do corte manual pelo 
mecanizado, os trabalhadores precisaram realizar outras atividades, nas quais não deixaram de laborar de forma precária, sem carteira assinada, na informalidade e com grande perda salarial.

É importante considerar que esse processo não ocorre apenas na Microrregião de Ituiutaba, mas em todas as regiões produtoras de cana no Brasil que se adequarão ao protocolo ambiental, de forma a extinguir as queimadas até 2018 e, consequentemente, o fim do corte manual da cana. Assim como em outros lugares, os cortadores de cana não tiveram acesso a cursos de preparação para outras atividades, o que representa um grande impacto social do processo de mecanização. Pelo perfil dos entrevistados, a maioria não possui escolaridade e isto dificulta a consecução de outros empregos, principalmente, com carteira assinada.

Por fim, fica evidente que os trabalhadores cortadores de cana-de-açúcar que durante décadas foram utilizados como mão-de-obra precária para manter a atividade em expansão, tem sido, substituídos pelas mecanização, sem perspectivas para assumirem novos postos de trabalho que sejam menos precários que nos canaviais.

\section{REFERÊNCIAS}

ALVES, G. Crise estrutural do capital, trabalho imaterial e modelos de competência: novas dialéticas. In: ALVES, G. et al. (Org.). Trabalho e educação: contradições do capitalismo global. Maringá: Práxis, 2006. p. 47-81.

ANTUNES, R.; SILVA, M. A. M. (Org.). 0 avesso do trabalho. São Paulo: Expressão Popular, 2004. p. 29-77.

COVER, M.0 "TRANCO DA ROÇA" E A "VIDA NO BARAC0": um estudo sobre trabalhadores migrantes no setor do agronegócio canavieiro.2011.184p.Dissertação (Mestrado em ciências Sociais). Universidade Federal de Campina Grande, Programa de Pós-graduação em Ciências Sociais, Campina Grande,2011.

DAL GALLO,P,M. A experiência de ser migrante: entre identidades e transitoriedades.2010.71p. Monografia em Geografia. Universidade Estadual de Campinas, Instituto de Geociências,2010.

IBGE. Produção Municipal de Minas Gerais 1990/2014. Disponível em: < http://www.ibge.gov.br, 2015>. Acesso em: 15 abr. 2015.

MARX, K. 0 Capital: crítica da economia política - O processo de produção do Capital. Tradução de Regis Barbosa e Flávio R. Kothe. São Paulo: Nova Cultural, 1996.

MATOS, P. F. As tramas do agronegócio nas “terras" do Sudeste Goiano. 2011. 355 f. Tese (Doutorado em Geografia) Instituto de Geografia, Universidade Federal de Uberlândia, Uberlândia, 2011. 
MENDONÇA, M. R. A urdidura do capital e do trabalho nas áreas de Cerrado. In: THOMAZ JUNIOR, A.; OLIVEIRA, A. M. S. de; GONÇALVES, M. A. (Org.). Geografia e trabalho no século XXI. Presidente Prudente: Centelha/ CEGeT, 2007. p. 84-106. 2007, v. 3.

RAMALHO,C,C.Os migrantes cortadores de cana do vale do Jequitinhonha: entre a superexploração e a resistência.114f. Dissertação (Mestrado em política Social).Universidade Federal do Espirito Santo, Programa de pós graduação em política Social,Vitória,2014.

SANTOS, M. A natureza do espaço: técnica e tempo, razão e emoção. 4. ed. São Paulo: HUCITEC, 2006.

SILVA, M. A. M. Errantes do fim do século. São Paulo: Fundação Editora da UNESP, 1999.

Se eu pudesse eu quebraria todas as máquinas. In: ANTUNES, R.; SILVA, M. A. M. (Org.). 0 avesso do trabalho. São Paulo: Expressão Popular, 2004. p. 29-77.

Trabalho e trabalhadores na região do "mar de cana e do rio de álcool”. AGRÁRIA, São Paulo, n. 2, p. 2-39, 2005.

SANTOS,A,P. 0 moinho satânico do agronegócio canavieiro no Brasil: dependência e superexploração do trabalho na região de Ribeirão-SP.2013.303p.Tese (Doutorado em Sociologia). Universidade Estadual de Campinas, Programa de Pósgraduação em sociologia do Instituto de Filosofia e Ciências Humanas, Campinas,2013.

SOUZA, A. G.; CLEPS JR, J. O desenvolvimento da agroindústria canavieira no Triângulo Mineiro e seus impactos sobre mão-de-obra e a produção de alimentos. In: ENCONTRO NACIONAL DE GEOGRAFIA AGRÁRIA, 19, 2009, São Paulo. CD ROM...São Paulo, 2009, p. 1-16.

THOMAZ JUNIOR, A. A. Por trás dos canaviais os nós da cana: a relação capital x trabalho e o movimento sindical dos trabalhadores na agroindústria canavieira paulista. São Paulo: Anablume/FAPESP, 2002. 